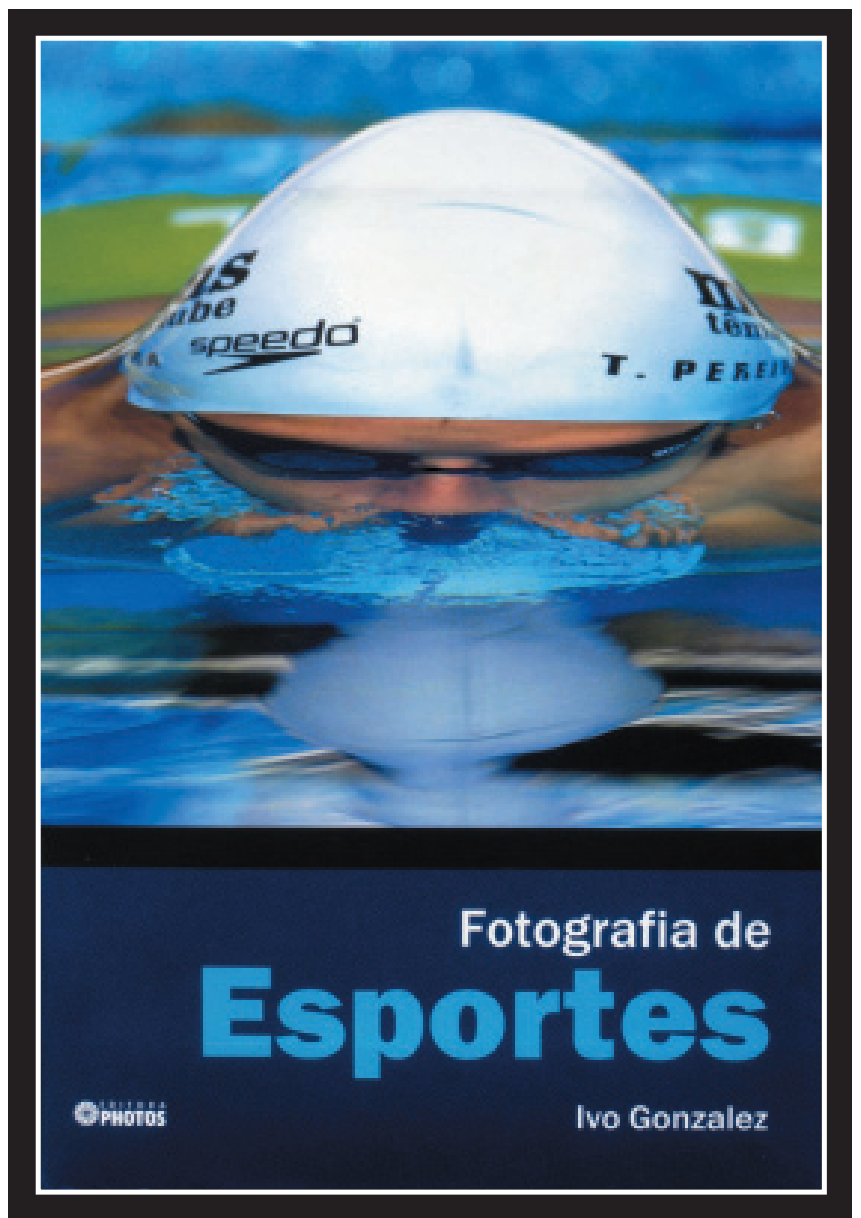

Fotografia de esportes, de Ivo Gonzalez.

Balneário Camboriú: Editora Photos, 2009. 320 p. 


\title{
A fascinante fotografia de esporte nas lentes de Gonzales
}

\author{
Flora Neves*
}

Ivo Gonzales é um jornalista que faz da fotografia de esporte sua profissão e paixão. Formado pela Pontifícia Universidade Católica do Rio de Janeiro, ao contrário de muitos profissionais da área, primeiro se dedicou à produção da imagem em movimento como repórter cinematográfico da TV Globo, porém logo descobriu que o fotojornalismo seria, de fato, a sua realização pessoal e profissional.

São 21 anos como repórter fotográfico, sendo quase 20 dedicados a coberturas esportivas. Na bagagem, Gonzales acumula os maiores eventos esportivos do planeta, entre eles, copas do mundo e olimpíadas, tornando-se um dos maiores especialistas neste tipo de fotografia. Pela primeira vez, ele socializa seu cotidiano, experiência e acervo no livro Fotografia de Esportes, lançado este ano pela editora Photos.

O livro reúne 312 páginas de um trabalho belíssimo em plasticidade e leitura prazerosa. São fotografias incríveis de atletas em movimento nas mais diversas modalidades pelo mundo afora; destaque para as fotografias das equipes brasileiras que disputam desde certames locais até os campeonatos mundiais mais importantes de cada categoria.

A obra de Gonzales está recheada da sensibilidade fotojornalística: além de utilizar os melhores recursos, transcende a técnica e envereda pela estética para mostrar as emoções de cada atleta ou a exuberante paisagem envolvendo cada competição. As imagens dos vários momentos e ídolos do esporte levam, até mesmo aqueles que não são apaixonados por esporte, a relembrar e vivenciar em cada clic disputas como se estas estivessem acontecendo no momento da leitura. "A expressão do jogador

\footnotetext{
* Doutora em Ciências da Comunicação pela Universidade de São Paulo (USP). Professora do Mestrado em Comunicação da Universidade Estadual de Londrina (UEL).
} 
de futebol marcando ou perdendo o gol muitas vezes pode ter mais impacto do que uma foto de disputa de bola, a euforia de uma torcida muitas vezes é mais importante do que uma foto de uma jogada", afirma.

Nos dez capítulos e anexos do livro, o autor compartilha com o leitor 340 fotografias para, de forma didática, contar sobre a experiência do fotojornalismo de esporte, o papel do profissional nas coberturas, uso de equipamentos e recursos. Mostra, detalhadamente, as técnicas de produção das fotografias mais radicais, sua edição e transmissão. Destaca, em cada legenda, os recursos para a produção, desde o tipo de objetiva e acessórios, até a abertura e velocidade na exposição.

No primeiro capítulo, dirigido aos aspirantes à carreira, o livro desmitifica a imagem de glamour e privilégios que envolvem a profissão do fotógrafo de esporte. O jornalista relata os entraves e dificuldades que o profissional encontra numa cobertura esportiva, desde a organização da viagem até a responsabilidade na seleção do "momento certo". Já no segundo, são mais de 50 páginas dedicadas a explicar o emprego do foco na fotografia de esporte. O capítulo é um verdadeiro curso de utilização de recursos das máquinas profissionais para ajuste do foco perfeito, e não é para menos: "Manter em foco um elemento que se move rapidamente é um desafio que o fotojornalista enfrenta constantemente", adverte.

O autor faz uma viagem no tempo (não muito distante) e compara os equipamentos, recursos digitais e analógicos no terceiro e quarto capítulos. A evolução da tecnologia digital, as características, vantagens e desvantagens das câmeras fotográficas mais próximas do trabalho fotojornalístico são os destaques. Gonzales lembra, na página 93, a resistência dos fotógrafos em usar as câmeras digitais, em função da qualidade do produto final, e pontua que as primeiras, com condições de serem usadas em coberturas esportivas, embora ainda lentas, foram lançadas em parceria entre a Kodak, Nikon e Canon e utilizadas em 1996, nas Olimpíadas de Atlanta, nos Estados Unidos.

As 140 fotografias selecionadas para o quinto capítulo retratam imagens deslumbrantes: expressões de atletas, focos em primeiro e segundo 
planos nos mais diferentes posicionamentos, ângulos e enquadramentos. Tudo para exemplificar, por meio da experiência pessoal, como o profissional ganhou em qualidade e tempo, ao absorver a tecnologia digital. O autor relaciona, dentro do capítulo, todo o equipamento necessário para qualquer cobertura jornalística de destaque no esporte: os modelos e especificidade de câmeras, as objetivas, flash, e outros acessórios.

Nos capítulos seis, sete e oito são organizadas, didaticamente, as técnicas de produção de uma boa fotografia, em que se escolhe a velocidade adequada e a configuração de gravação do arquivo. Cada texto vem acompanhado de imagens exemplificando o trabalho descrito. A experiência de Gonzales é exibida com tanta precisão, que ele chega a detalhar, no penúltimo capítulo, como são organizadas as coberturas esportivas, as dificuldades e problemas pelos quais o profissional passa: desde o credenciamento na hora de fazer o trabalho até o espaço físico para a produção e transmissão das imagens.

Todas as orientações dos capítulos são ilustradas com fotografias esportivas "de tirar o fôlego". Difícil, inclusive, escolher, caso fosse necessário, as mais perfeitas ou mais bonitas. Em vários momentos, deparamo-nos com imagens de atletas congelados no ar, corredores sendo lançados no espaço com suas motos, silhuetas de skatistas, surfistas ou alpinistas inseridas na deslumbrante paisagem do Rio de Janeiro.

Na finalização do livro, Gonzales dá orientações básicas para quem tem pouca experiência com a fotografia. São "dicas" de equipamentos mais simples e baratos para fotografias "descompromissadas", uma forma do iniciante se familiarizar com a fotografia de esportes. Na página 270, ele recomenda:

O melhor é sempre procurar alguma competição ao ar livre, $[\ldots]$ outros esportes radicais como o voo livre também são adequados para o fotógrafo amador. As técnicas de posicionamento, controle de luz, ajustes de fotometragem, por exemplo, muitas vezes são as mesmas para se conseguir uma boa foto de futebol, tanto num jogo do Maracanã como num jogo de campeonato na escola do seu filho. 
O brinde final é uma seção de 39 fotografias com cenários perfeitos, lances nunca exibidos e que juízes de futebol, por exemplo, nunca viram. São closes de atletas, no auge das conquistas, comemorando gols, vitórias, transbordando toda a sua emoção. Detalhes possíveis só pelas lentes de Gonzales e que fazem do livro uma deliciosa aula de fotojornalismo especializado.

De fato, o autor, além de oferecer, na obra, um curso completo de fotografia de esporte, aproveita para mostrar sua capacidade, qualidade profissional e paixão. Não é "à toa" que os editores do jornal com os quais o jornalista trabalhou, no início da carreira, diziam sobre o material de Ivo Gonzales: "Eram fotos com enquadramentos radicais, precisos, fotos prontas, o resultado que todos os fotógrafos buscam." 